\title{
Portfolio Management using Primavera P6 through Web Integration
}

\author{
Anuja Narayanan, Mathesh Raja Sankar
}

\begin{abstract}
Increase in population increases the demand for dwelling with a greater comfortness with all amenities. Nowadays people require residential building with fitness center, balconies, laundry room, swimming pool, childcare center, playground, and community room. The demand of people initiated to construct a apartment buildings in major cities. The process of planning and schedule of the activities in the construction of apartment building should be in a logical and systematic manner which is done using Autocad and Primavera P6 software. Finally the web integration is done for scheduling the major resources in the construction work which in hand manage the time period effectively.
\end{abstract}

Keywords: Resources, Planning, Scheduling, Portfolio Management

\section{INTRODUCTION}

$\mathrm{P}$ lanning and scheduling is are that are often thought of as synonymous.. Scheduling is just one part of the planning effort. The term planning are used indifferent contexts. The financial planning, are retirement planning and college education planning. Although they may include other aspects, the main focus are on finance. Government, and large corporations, has planning units and teams in almost every department. At most of individual level, young person have plans for marriage, career, and so on. However, the term planning is restricted to meaning project planning, with an emphasis on construction projects.

Before project planning, we need to define a project. The Project Management Institute (PMI 2008) is temporarily undertaken to create unique product, service'. The keywords in this definition are temporary and unique: any project must have a starting point and an ending point, and it must have a deliverable product or service that is unique. The PMI defines a program as "A group of related projects managed in coordinated to obtain benefits and control not available from managing them individually. Programs may include elements of related work outside of the scope of the discrete projects in the program." (PMBOK 2008)

Programs may be:

\footnotetext{
Manuscript received on 12 March 2021 | Revised Manuscript received on 21 April 2021 | Manuscript Accepted on 15 July 2021 | Manuscript published on 30 July 2021.

* Correspondence Author

Anuja Narayanan*, Assistant Professor, Department of Civil Engineering, Mepco Schlenk Engineering College, Sivakasi, Tamilnadu, India.Email: anujacivil@mepcoeng.ac.in

Mathesh Raja Sankar, UG Student, Department of Civil Engineering, Mepco Schlenk Engineering College, Sivakasi, Tamilnadu, India. Email: matheshdevi8@gmail.com

(c) The Authors. Published by Lattice Science Publication (LSP). This is an open access article under the CC-BY-NC-ND license
} (http://creativecommons.org/licenses/by-nc-nd/4.0/)
London May have all construction projects for 2012 Summer Olympics under 1program. Once program ends with the completion of its projects; by the opening of 2012 Summer Olympic Games, it will be completed then closed. The maintenance of these facilities, later on, is a different matter. Ongoing (usually periodic/annual) programs: These include projects such as road maintenance and storm water programs for public works department in many municipalities. Many private and public institutions have maintenance programs for their existing facilities. Such a program usually has annual budget and it covers small projects-as the budget allows. The program usually lives as long the facility does. One important note: In the UK, as well as in some other countries that use British terminology, the schedule (timeline) of the project is called program. This is not the program that we are discussing.

Portfolio: This is a group of projects, not necessarily related or dependent, usually under one project manager or department. The PMI defines it as "A collection of projects or programs and other work that are grouped together to facilitate effective management of that work to meet strategic business objectives. The projects and programs of the portfolio are not independent or whether directly related.' (PMBOK 2008).

Subprojects: These are project that are divided by their specialty, responsibility, phase, area. To the person in charge of subproject, the subproject is a project, except that consideration not only the internal relationships among its activities but the external relationships as well. For example, in residential and commercial development project, building the infrastructure may be regarded as a subproject. In fact, building the sewer system in the development can be a subproject or even a sub-subproject. Are Projects Unique? Some people may think of two construction projects as identical just because they have same design. In project management, we may have similar projects, but every project is unique.

Differences may come from a difference in location according to soil type, weather conditions, labor market, building codes, unforeseen conditions, etc., in management type and experience, or in certain circumstances. Project planning has been defined as "the process of method and work to be adopted for a project from all the various ways and sequences in which it could be done'". The PMI defined the planning process in the PMBOK in the year 2000 as "Those processes which are performed to establish the total scope of the effort, define the objectives, and develop the course of action required to attain objectives" Project planning serves as a foundation for several related functions, such as cost estimating, scheduling, project control, quality control, safety management, and others.

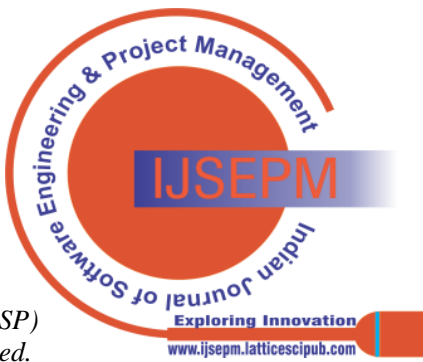


Scheduling is the determination of the timing and sequence of operations in the project and their assembly to give the overall completion time. As mentioned, scheduling focuses on the planning effort. The Project planning answers the questions What is going to be done? How? Where? By whom? and When? Scheduling deals with when on a detailed level. In fact, scholars have generally separated planning from scheduling "CPM separates planning and scheduling, and once project information is collected and expressed as a network plan and activity time estimates assigned, CPM calculations can be made. Planning ceases and scheduling starts when the first computation is performed that shows a project duration. The project duration is then compared with the desired schedule and scheduling begins."

\section{Project Control}

When a project starts, certain aspects can easily go astray. This deviation can be over spending, a schedule, departure from the objective/scope, or something else. It is of utmost importance to know at all times where you stand in relation to where you planned to be. If you find yourself behind schedule or over budget, you must know why and then take correct action to get back on track, at least, minimize the deviation. If the deviation is positive, actual performance was probably better than that expected in the baseline plan. This process exemplifies project control. Although the concept of project control covers all aspects of the plan which are including budget, schedule, quality, etc., our main focus in this book is on schedule and budget control, which are related.

\section{Scheduling and Project Management}

Planning, scheduling, and project control are extremely important components of project management. However, project management includes other components, such as cost estimating and management, procurement, project administration, quality management, and safety management. These components are all interrelated in different ways. The group of people representing all these disciplines is called the project management team. It is usually headed by the Project Manager (PM).

\section{LITERATURE REVIEW}

Construction practice globally is characterized with challenges across processes and methods. It is evident also that the mechanism to mitigate those challenges have not resulted in the desire performances in the various construction industry. Further monitoring and evaluations of project has been encouraged as solution for solving the performance challenge, these factor influences effectiveness monitoring and the evaluation systems which been involved in the Ghanaian construction industry. This qualitative approach has been adopted to validate the factor influencing monitoring and their correction in Ghanaian construction industry (1).

Based on a longitudinal case study of three construction projects, this paper aims to present a holistic analysis on the RM learning process from the experience of a small-to-medium (SM) general contractor (GC) in China to explore the underlying facts determining the effectiveness of $\mathrm{RM}$ practices. It was found that a variety of causes led to rework in the three projects, which highlighted the importance to enhance GC's learning capacity to effectively reduce rework. A conceptual RM learning framework
(CRMLF), which consists people, approach, project and tools which was developed based on the analysis of influential factors of successful learning within the RM domain. This paper is valuable for practitioners and academics to understand the inherent nature of RM to continuously improve the project performance (2).

The time, cost and quality are crucial, conflicting aspects to construction project management. Trade off optimization among project duration (time), project cost, and the project quality within the project scope is necessary to enhance overall construction project benefit. A novel optimization algorithm, Opposition-based Multiple Objective Differential Evolution (OMODE), is presented to solve the time-cost-quality trade off (TCQT) problem. This novel algorithm employs an opposition-based learning technique for population initialization and for generation jumping. This study is expected to provide an alternative solving methodology for the TCQT problem and help project manager plan construction methods with optimal time-cost-quality trade off(3).

Construction continues to be considered as one of the most dangerous industries in the world, in particular residential building construction. This paper aims at proposing an automated safety planning plug-in (ASPP) for project scheduling software applications to mitigate the occurrence of construction accidents. The practical implication of this study is to improve construction safety by promoting the project managers' awareness of safety hazards and relevant risks as well as essential safety measures provided through a comprehensive report from which managers can review essential safety measures to prevent possible construction accidents(4).

In this paper, an example of how new technologies can be used to improve the planning and design of buildings is shown. In the planning phases, case-based reasoning is used to identify similar completed projects that would enable faster starts of new projects. In the design phases, case-based design is used to identify similar portions of completed projects that would enable faster designs of the more detailed parts of the buildings. A proof of concept using housing projects from a design-build-operate company based in Switzerland is used to test the viability of the proposed system. It is shown that the CB-DBS enabled faster planning and design phases of new projects and improved exploitation of the knowledge gained in previous projects(5).

In the design phases, case-based design is used to identify similar portions of completed projects that would enable faster designs of the more detailed parts of the buildings. A proof of concept using housing projects from a design-build-operate company based in Switzerland is used to test the viability of the proposed system. It is shown that the CB-DBS enabled faster planning and design phases of new projects and improved exploitation of the knowledge gained in previous projects(6).

The construction industry which provides large-scale employment is the foundation of development for emerging countries like India. The productivity of the construction industry depends largely on resource management methods.

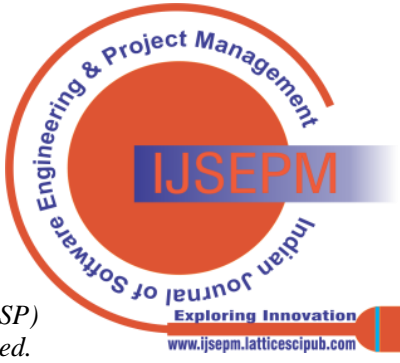


For construction project monitoring and control Primavera P6 turns out to be an effective tool because the time to upgrade is significantly reduced. This paper aims to provide a review on application of Primavera software in time and resource management of construction project. The study finds how Primavera P6 software solves various complexities associated with planning, scheduling, controlling, monitoring and tracking of construction projects based on detailed literature survey(7).

Resource management is one of the most important aspects of construction project management in today's economy because the construction industry is resource-intensive and the costs of construction resources have steadily risen over the last several decades. Thus general schedule control techniques are useful in optimizing resource scheduling and project duration. These techniques help to reduce project duration use of unlimited availability of resources for completion of a project. Through it is observed that resources are limited in real project scenario. It has been observed that the project delays occur due to insufficient supply of resources. In large scale projects, preparing an accurate and workable plan is very difficult(8).

The purpose of this project is to optimize the resources by using the methods "Resource allocation, Resource levelling, time cost trade off". Resource allocation is used to assign available resources in an economic way. Resource allocation is the scheduling of activities and the resources required by those activities while taking into construction both the resource availability and the project time. Time cost trade of is project duration can be reduced by assigning more resources to project activity. Doing this however increases project cost. The critical path method is used for scheduling a set of project activities. The analysis of resources also done by using primavera software(9).

In Project Management, proper arrangement and setting up is very essential element. Planning is a base for each and every work in management field. It serves as base for executing, monitoring and controlling and closing. When quality time is spent on planning, it will fundamentally minimize the time spent on execution. Planning manages chalking out a future strategy and choosing ahead of time the most suitable course of activities for accomplishment of predefined objectives. This paper deals with the planning, scheduling and tracking of a residential building at New town, Yelahanka which has 116 flats $(\mathrm{G}+4)$ where construction is in progress. This paper also ensures a comparison between the baseline duration and cost to actual duration of project using project management software tool Primavera P6(10)

Although the long-introduced Industrialized Building System (IBS) has promised to solve and improve the current construction method and scenario in our country, but the IBS method has not gained enough popularity. One of the reasons is due to lack of research works done to quantifying the benefit of IBS especially in construction time saving. In lieu with such scenario, this study conducted to quantify evidence of time saving in IBS application. Primavera P6 is amazing software, which is used not just by planners, but also managers, engineers, schedulers, and anyone else involved in planning, management, reporting of a project. Primavera P6 has benefited every industry from aerospace to manufacturing, electronics to IT(11),

\section{WORK ANALYSIS}

\section{Planning}

Planning is the essential and challenging activity in management and execution of the construction projects according to the desired plan. They provide the technology, work tasks, estimation of resources and durations for the each tasks, and the identification of interactions among the different work tasks. A good construction plan is the basis for developing the budget and the schedule for work. Development of the construction plan and its critical task involved in the management of construction, and if the plan is not provided or recorded.

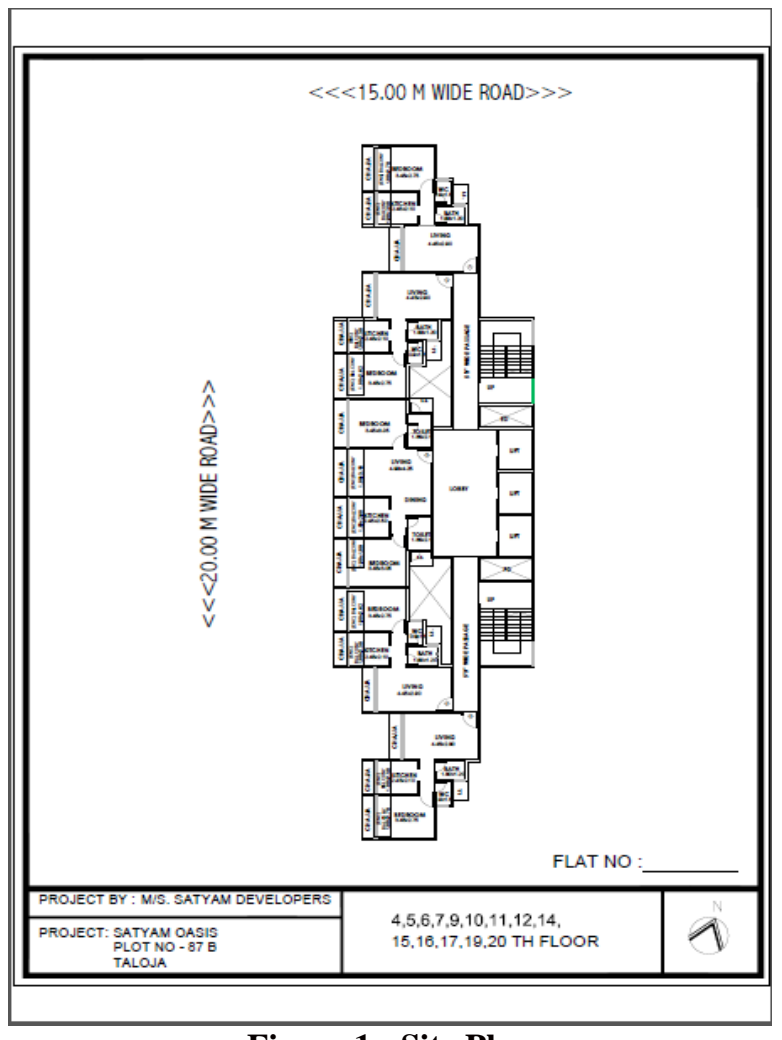

Figure 1 : Site Plan

The various aspects of construction planning, is also very essential to make important decisions about inter relationships between projects and even what programs to include in a project. The below figure 1 represents the construction site at Mumbai region. Three dimensional geometric models in a computer aided design (CAD) system may be helpful in simulating space requirements for operations and for identifying any interferences. Similarly, problems in resource availability identified during the simulation of the construction process might be effectively forestalled by providing additional resources as part of the construction plan. The upcoming plan in the figure 2 represents the building construction site.

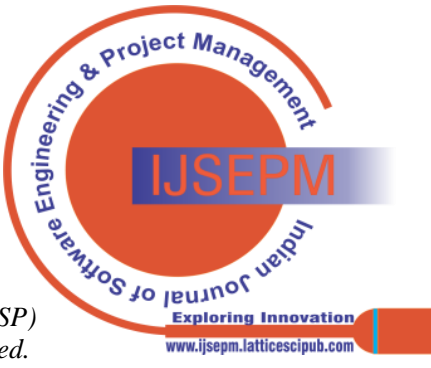




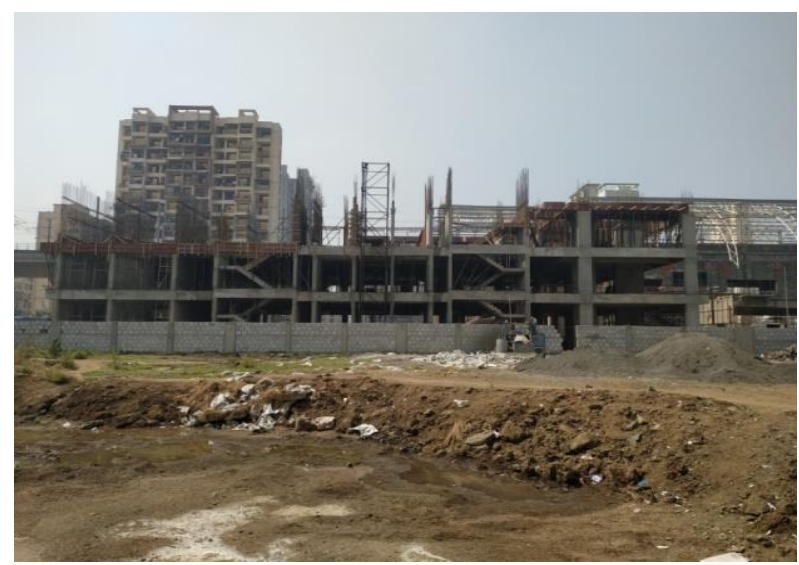

Figure 2: Construction Site at Mumbai

\section{Scheduling}

The bar chart was originally developed by Henry L. Gantt and is also called as Gantt chart. It made a big impact especially in the construction industry because of its ability to graphically present a project's activities on the correct time scale. Before a bar chart can be constructed for a project, the project must be broken into smaller, usually homogeneous and heterogeneous components, each of which is called an activity, or task of specified and featured databases. There is no elegant way to make it correct or incorrect way to break down a project which exists; however the scheduler should take a balanced decision to approach and break it down into a reasonable number of activities that can be easily measured and controlled without being detailed specifically, as large as laying the foundation of a building, as small as erecting the formwork and the shuttering work of one footing, or anywhere in between.

The duration of each activity must be estimated by the time scale. Bars are then drawn to show, for each activity, the duration and the starting and ending points. As mentioned, links between activities are not usually shown. On a bar chart, the bar may not indicate continuous work from the start of the activity until its end. For example, the activity getting a Building Permit may be represented by a 2-month-long bar. However, most of this time is a waiting period. Bar charts have become a vehicle for representing many pieces of a project's information. Many variations of bar charts have evolved; some simply show the start and end of each activity, some are loaded with resource or budget numbers, and others compare the as-planned schedule. The following is the project which is scheduled by the means of the bar chart representation,

- At the initial step first we make the remedy steps like then opening of the new project and to fulfil the certain options as mentioned below the figure 3 which gives EPS and figure 4 represents project name.

- After entering the above screen we should enter the project id, project name, responsible manager, standard rate of the project and the start to end time of the project .After entering all the above data press finish to complete the process of creating a new project. The figure 5,6 and 7 represents the manager selection term.

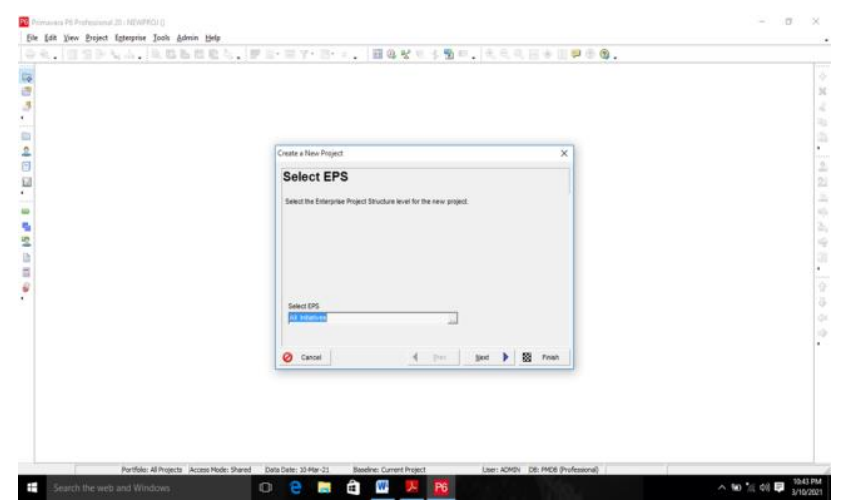

Figure 3 : Enterprise tool box

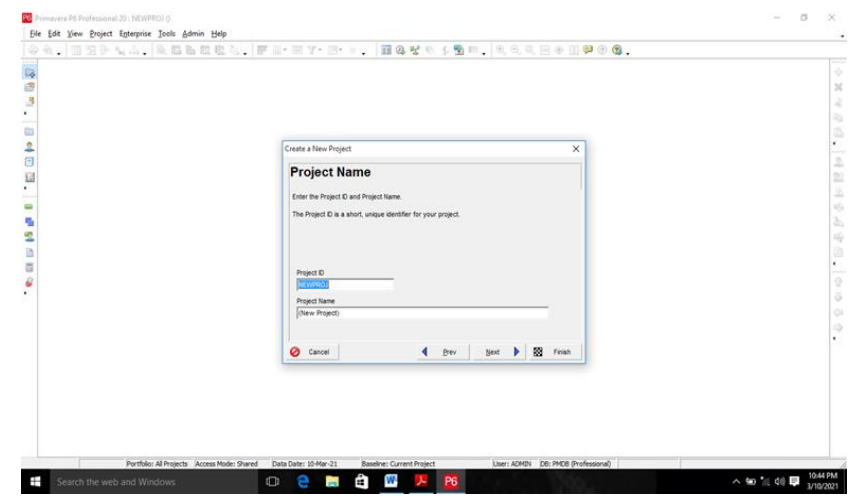

Figure 4 : New project

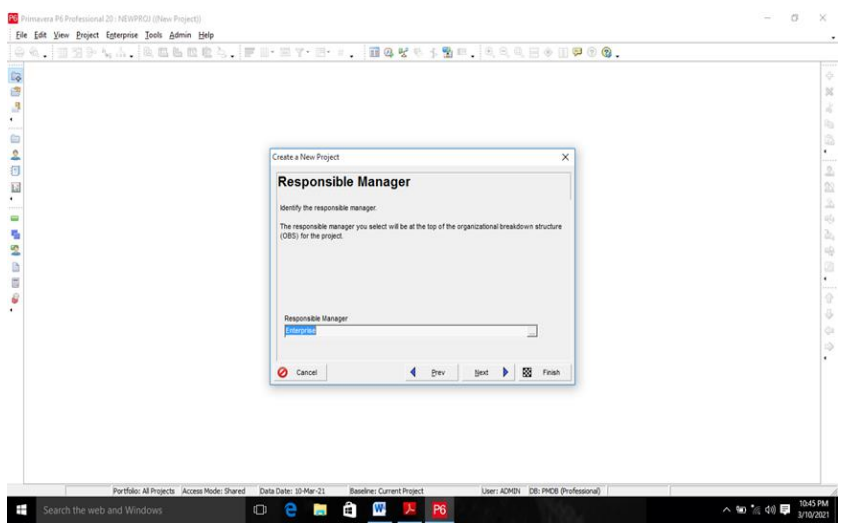

Figure 5 : Project manager selection

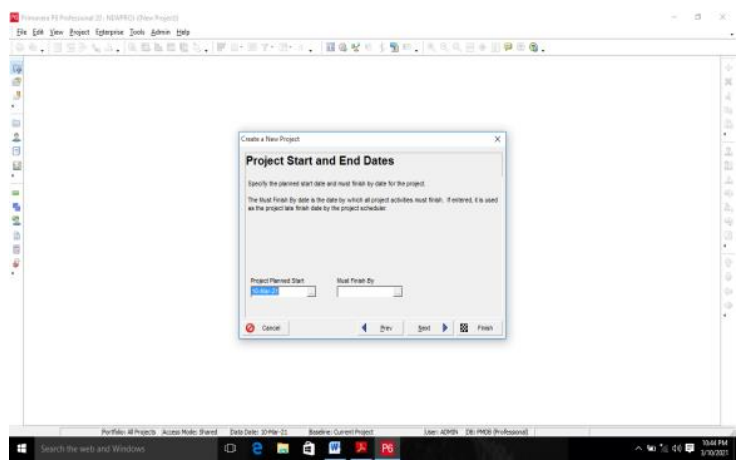

Figure 6 : Dates of the project of apartment building

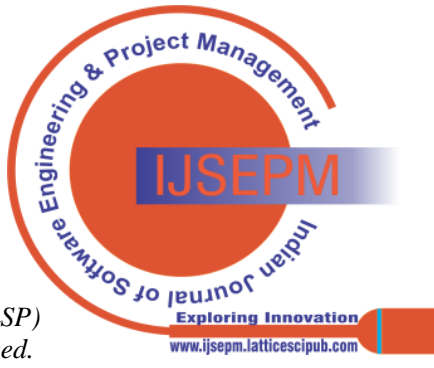




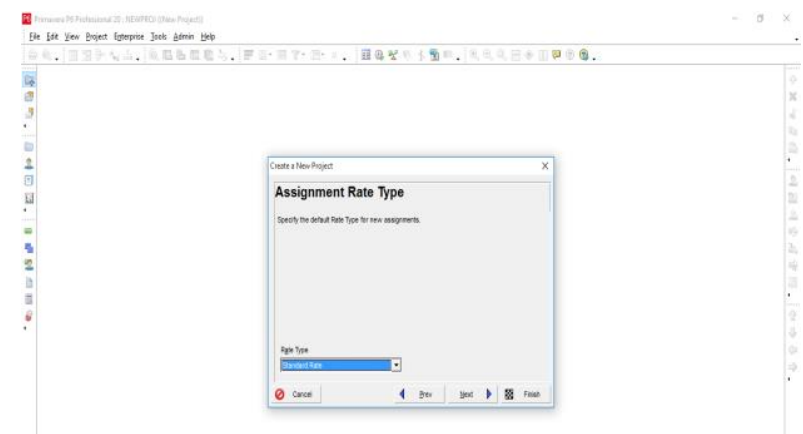

\#

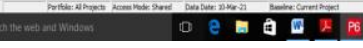

Figure 7 : Standard rate fixation

- Then after the interpretation of all the data enter the project and then we must enter the data in the sequence as per the work schedule and the work to be done and arrange them according their activity ID and then enter the duration and the dates specified for each work at the scheduled time and day and make them ensure that they are completed according to the scheduled work data otherwise the bar graph will be indicating the delay of the work. Change the option to the physical compliance to ensure that the bar graph gets adjusted to the live work completed.

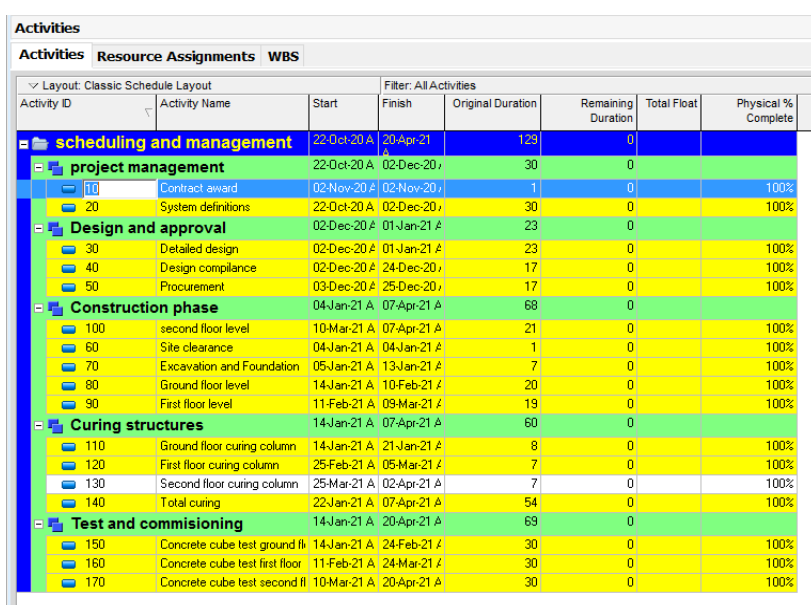

Figure 8 :Schedule of activities of apartment building

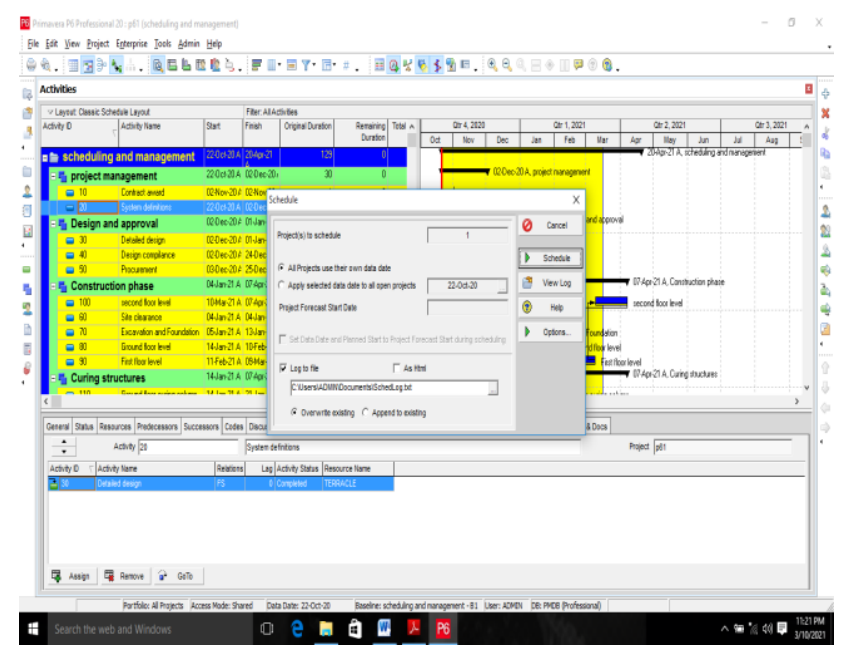

Figure 9: Schedule visualizer

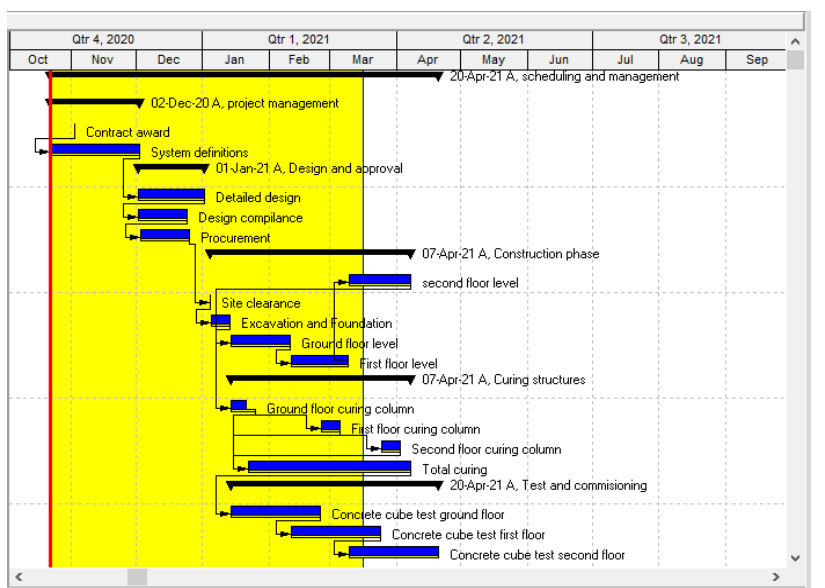

Figure 10. :Bar chart of activities

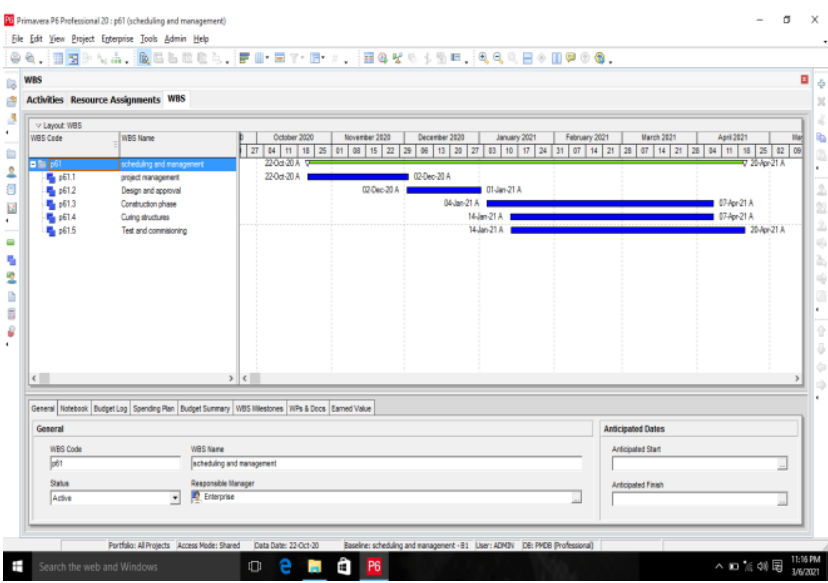

Figure 11 :WBS of apartment building

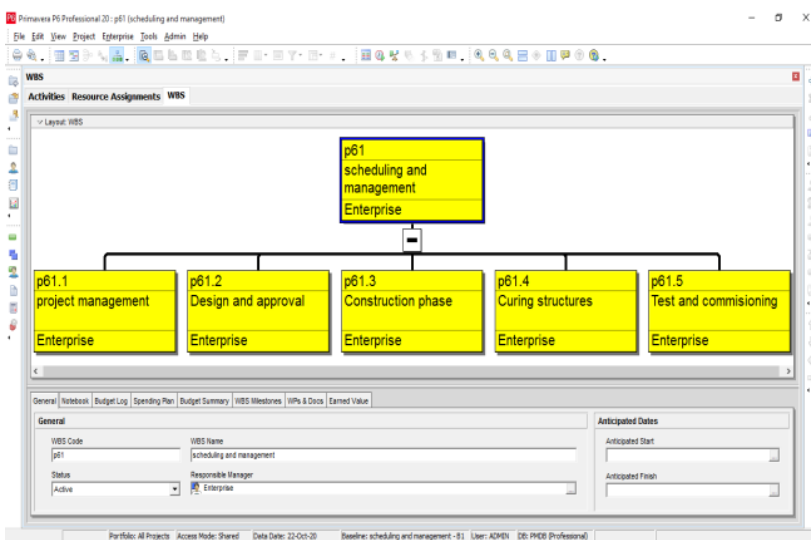

a

Figure 12:WBS layout of apartment building

- Then after the complete interpretation the bar graph gets scheduled according to the given time line and then the sequence gets completed by the physical percentage completion of the work .Then to schedule the data given we need to enter the visualize schedule option and enter the option "All projects enter their own data date" and then give ok to complete the scheduling process. The following operation is given below in the figure 8 which represents scheduling, 
The above figure 9-12 represents the process and Work Breakdown Structure of the apartment building which represents the sequence of the activities of the particular project and they are very helpful in project management and systems engineering which is a deliverable-oriented breakdown of a project into the smaller components. A work breakdown structure is a key project deliverable that organizes the team's work into manageable sections. The main purpose is they act as a tool that can be used for this project, programs and even initiatives to understand the work that has to be done successfully. Therefore they define and organize then works to be done. The above portfolio describes the activities in the sequential categorized based on their duration and hierarchal sequence. The project is titled as the p61 test and each tab consist of the sequence of the activities listed as shown and it also determines its process based on the work progress.

\section{PORTFOLIO MANAGEMENT THROUGH WEB INTEGRATION}

The web integration is the process by which the outputs and the other data regarding the activities and their components which are essential for carrying out the web project. This is a beautiful platform which connects the client and the other customers for essential detailing of the required projects and for the better understanding of the project and for the convenience of the customers and the clients. This is a simple and the most precise website to manage the planning and scheduling of the building plan. This website is designed with below menus for the attraction .Home $\backslash$ About-Display information about the project and the site location. This is similar to that of the google forms which collects the input from the user to prepare the sequence of the activites. The scheduling of the activities is being projected by entering the certain data of the project as an input over the particular website and then the output of the data of being downloaded and being displayed to the clients .It also displays the other services about our projects and it helps in the development for the future enhancement. And further the contact details of the construction company are also provided.

\section{Methodology and process}

This website is hosted on the Site $\mathbf{1 2 3}$ and is a good solution for many projects like small portfolios and business websites. This website is designed with the site 123 template which helps to get input from the user .This in built template has a prototype to add our content. This website template creates the pages for this projects and then they provide text boxes on the schedule activities in the page. The scheduling of the activities by the step by step process is explained in the detailed manner as given below Then at the first step we need to enter the respective URL which has been created by certain coding languages and the click enter in the browser. The URL is https://604a12a535436.site123.me/. Then after entering the respective url the portfolio gets displayed in the browser Then after the portfolio gets displayed in the browser it shows the certain info about the project done to the clients and the other viewers which provides them a better understanding about the project and this enhances the business in the future. The portfolio displays the contact details and the other details like schedule of activities as shown in the figure 13 which represents the portfolio display of the building,
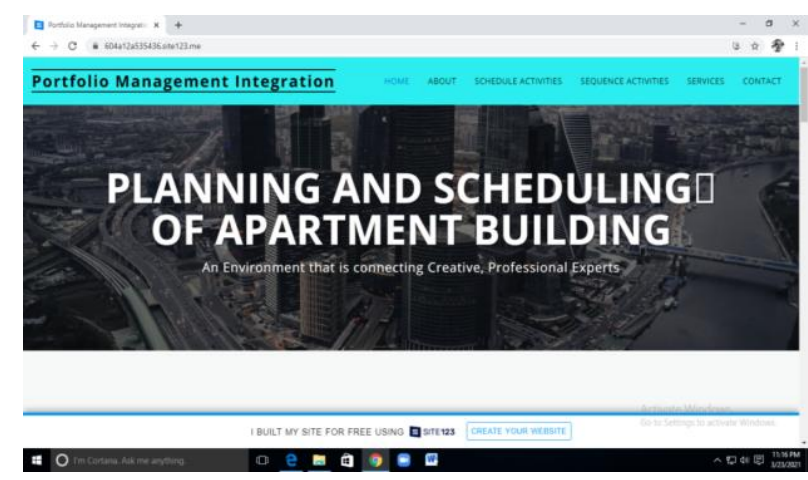

Figure 13 : Portfolio display of the apartment building

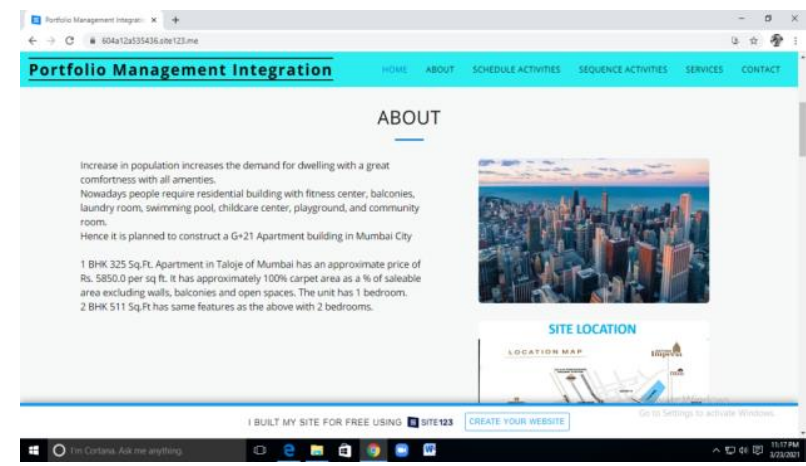

Figure 14 : Details of the project

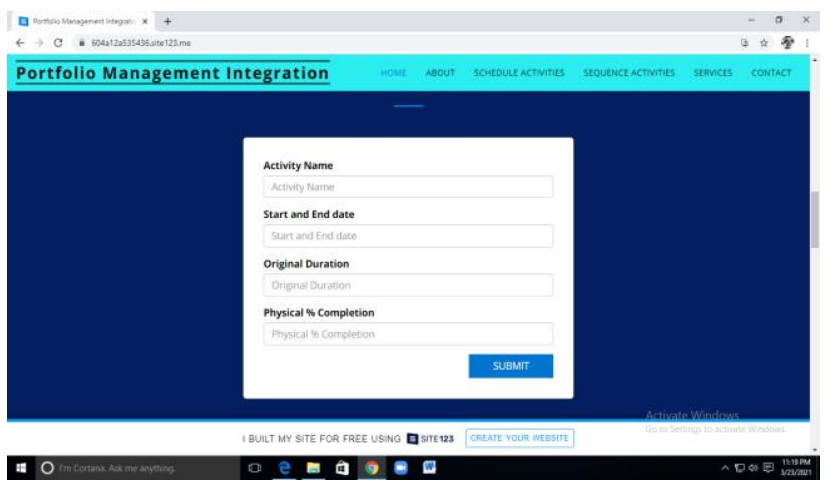

Figure 15 : Input data for the activities

Then after viewing the entire portfolio we scroll down and it describes about the company details like location ,geological conditions and the other data like site details ,project details, number of plots available in the project and the building details and they are of the building and the rate of the each unit in terms of square feet. These information's are listed in the given figure 14 which represents details of project, Then after the provision of the site details and building details then we will be having a slot of blank space for entering the activity data which will interpret with the results provided and then after entering the activity specifications we have to click the SUBMIT and the DOWNLOAD option and then we will be able to have our sequence of the activities in figure 15 gives input data for the activities

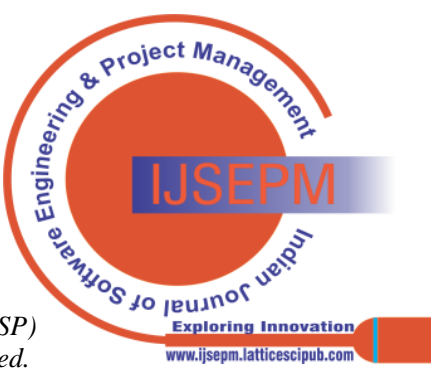




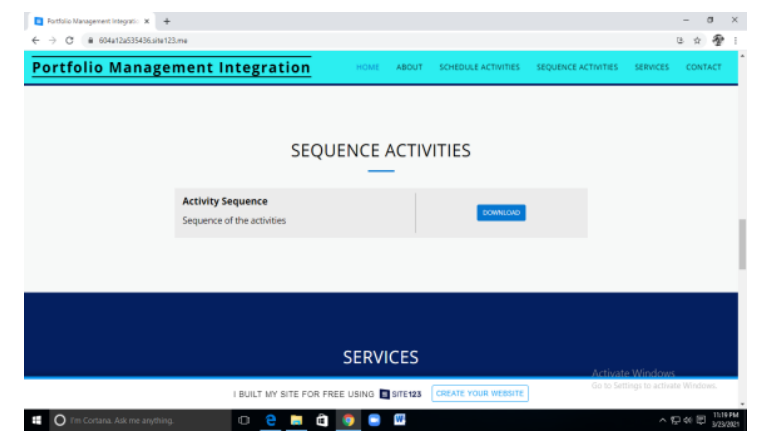

Figure 16 : Activity sequence of apartment building

The interpretation of the results takes place after giving the enteries for the certain activity id along with the start and end dates which is provided for the particular activity and also tha original durartion for the each tasks which is being taking place and percentage of the work completed.Then simultaneously the succeding activity details which is being completed is entered and then they are submitted for the data interpretation and then after clicking the download option we will get the whole sequence and will be downloaded.The figure 16 represents the activity sequence of apartment building, Further we will get the activity sequence and the client will be able to see it through this website and vice versa.

\section{CONCLUSION}

The planning and scheduling process in the construction of G+21 Apartment building which is located in Taloje, Navi Mumbai is characterized as following:

- The type of soil present in the site is of Murum which is rich in aluminium and iron. The Safe Bearing Capacity of the soil is $80 \mathrm{~T} / \mathrm{m}^{2}$.The Total area of the site is of 0.58 acres (ie the built up area is 1100 square meter and the plot area is 2500 square meter).

- Apartment units is of 82 and are available in various configurations like 1 BHK flats at a price of Rs $34.51 \mathrm{~L}$ with Property size of $325 \mathrm{Sqft}, 2$ BHK flats at a price of Rs 54.25 L with Property size of 511 Sqft. The building is constructed as a 1 BHK 325 Sq.Ft. Apartment in Taloje of Mumbai has an approximate price of Rs. 5850.0 per sq ft. It has approximately $100 \%$ carpet area as a $\%$ of saleable area excluding walls, balconies and open spaces. The unit has 1 bedroom. 2 BHK 511Sq.Ft has same features as the above with 2 bedrooms.

- The structure is constructed as a Framed one with G+21 floors. AUTOCAD Software is used for drawing the plan and the process of scheduling is carried out in Primavera P6and the results are interpretated. A separate website is designed for the automatic prediction of scheduling process through the web link url is 604a12a53546.site123.me for better understanding between the clients and the organization.

\section{REFERENCES}

1. Tom, Andrew Fernans, and Sachin Paul. "Project monitoring and control using primavera."International Journal of Innovative Research in Science, Engineering and Technology 2.3 (2013): 762-771.

2. T. Subramani, A. Sarkunamand J. jayalakshmi "Planning and Scheduling of High Rise Building using Primavera” ISSN: 2248-9622, Vol. 4, Issue 6 (version 5), June 2014, pp. 134-144.
3. RhutaJoshil, Pros. V. Z. Patil (2013) "Resource Scheduling Of Construction Project: Case Study" International Journal of Science and Research

4. Andrew Fernans Tom, Sachin Paul (2013) "Project Monitoring And Control Using Primavera" International Journal of Innovative Research in Science, Engineering and Technology

5. Ragendra, (2016), "Schedule Control of an Apartment Building using Primavera Techniques", International Journal of engineering research and technology, 5(6), pp: 822- 825 [CrossRef]

6. T.Subramani, (2015), "Construction Management and Scheduling of residential building using primavera", International Journal of application in engineering and management, 4(5), pp: 188-198.

7. Unmesh. Y. Polekar(2015),"Planning, Scheduling, and Tracking of a residential Project using Primavera Software", International Journal of advanced research in computer science and management studies, 3(5), pp:227-236

8. Patil, (2013), "Resource Scheduling of construction project: a case study", International Journal of science and research, 4(5), pp: 563-568.

9. HamedZiaidoostan, (2013), "Using Primavera software in resource allocation and project evaluation of construction project

10. Vignesh, "Resource optimization of construction project using primavera p6", Iosr journal of mechanical and civil engineering (iosr-jmce) e-issn: 2278-1684,p-issn: 2320-334x, Vol. 14, issue 1, 2017, pp 01-08. [CrossRef]

\section{AUTHORS PROFILE}

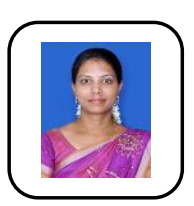

Dr.N.Anuja, is currently working as an Assistant Professor in the Department of Civil Engineering, Mepco Schlenk Engineering College (Autonomous), Sivakasi. She completed her B.E (Civil Engineering) in Government College of Engineering, Tirunelveli and M.E (Construction Engineering and Management) in St.Xaviers' Catholic College of Engineering, Nagercoil. Then she continued her career in the teaching field as an Assistant Professor in the Department of Civil Engineering in Arunachala College of Engineering for Women, Nagercoil for 2 years. Then she pursued her Ph.D in Full-Time with DST Inspire Fellowship, New Delhi in the Department of Civil Engineering, Mepco Schlenk Engineering College (Autonomous), Sivakasi which is affiliated under Anna University, Chennai. She has successfully completed her research work with 3.5 years experience and has been awarded as Doctorate in Civil Engineering in 2018. She is a recognized supervisor of Anna University, Chennai from 2019.

Her area of expertise includes: Geopolymer Concrete, Advanced Concrete Technology, Advanced Construction materials, Modern Construction Materials. She has also filed two patents which are at examination level. She has presented 9 papers at various symposiums and conferences and published one paper in IEEE proceedings. She has guided 6 mini projects, 8 design projects and 9 experimental projects at UG level and 1 mini project along with 3 experimental projects at PG level. She is the author of 18 International and National journals and she is also acting as a Reviewer in 20 International and National level Journals and as an Editorial Board Member in 6 journals.

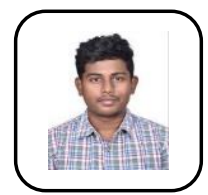

Mathesh Raja Sankar, is an undergraduate student of Civil Engineering who studied in the Department of Civil Engineering, Mepco Schlenk Engineering College, Sivakasi during the academic year 2017-2021. He did his final year project under the specialization of project management by undergoing a field based training through intern in a Construction Site located in Mumbai.

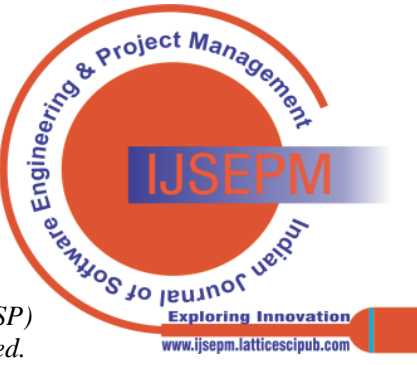

